\title{
Positron emission tomography in venous ulceration and liposclerosis: study of regional tissue function
}

\author{
N F GOWLAND HOPKINS, T J SPINKS，C G RHODES，A S O RANICAR，C W JAMIESON
}

\begin{abstract}
Oxygen-15 administered by continuous inhalation and emission computed tomography were used to study regional tissue oxygen utilisation and blood flow in the limbs of 11 patients with venous ulceration and five patients with liposclerosis due to venous insufficiency. The results showed increased blood flow and appreciably reduced fractional oxygen extraction in the diseased tissues.

These findings indicated a local, functional shunting of blood through the abnormal microcirculation of the skin and subcutaneous tissues. This may be an important factor in the aetiology of the skin changes seen in patients with calf muscle pump failure.
\end{abstract}

\section{Introduction}

The mechanisms which lead to the skin changes of venous disease of the leg are not fully understood. Investigation of affected legs shows that the calf muscle pump fails, and this leads to a high venous pressure in the foot, which is sustained during exercise. Early theories suggested that a high venous pressure slowed capillary blood flow and thus caused local tissue hypoxia, ${ }^{1}$ but analysis of venous blood gases shows high oxygen tensions, which does not support this theory. ${ }^{2}{ }^{3}$ These findings led to a search for arteriovenous shunts in the legs of patients with varicose veins and ulceration. Studies have shown abnormal fistulae ${ }^{4}$ and changes in the normal arteriovenous communications of the microcirculation of the skin, ${ }^{5}$ but these abnormalities have not been detected consistently. ${ }^{6}$ There is evidence, however, that the microcirculation is abnormal. Increased numbers of

Department of Surgery, Hammersmith Hospital, London W12 0HS N F GOWLAND HOPKINS, FRCs, surgical research fellow

T J SPINKS, PHD, scientific officer, MRC

C G RHODES, MSC, senior research officer

A S O RANICAR, MIST, technical officer

C W JAMIESON, MS, FRCS, consultant vascular surgeon capillaries have been shown in the skin and subcutaneous tissues of the ulcer bearing area of the leg, and this change has been correlated with pedal venous pressure after exercise.? These capillaries have increased permeability to fibrinogen ${ }^{8}$ and become surrounded by a pericapillary fibrin cuff, which may impede the passage of nutrients to the skin and cause ulceration.

Jones $e t \mathrm{al}^{10}$ initially described the use of continuous inhalation of oxygen-15 to measure regional blood flow and oxygen extraction in tissues. Using emission computed axial tomography, Frackowiak et al ${ }^{11}$ extended this approach so that quantitative measurements of these physiological parameters could be made in the form of transaxial tomographic distribution.

We have applied this method to study the regional tissue function in the legs of patients with venous ulceration and lipodermatosclerosis, the induration of the subcutaneous tissues which accompanies venous hypertension.

\section{Patients and methods}

The patients studied attended the vascular unit of the department of surgery. All had normal arterial circulation as assessed by Doppler ankle blood pressure measurements. Each patient's venous circulation was studied using directional Doppler, strain gauge plethysmography, direct venous pressure measurements, and phlebography. All were found to have sustained venous hypertension during exercise due to either deep venous incompetence or superficial venous disease with incompetent perforating veins.

All studies were performed with the Hammersmith positron emission tomograph scanner. Scans were performed while continuously inhaling labelled carbon dioxide $\left(\mathrm{C}^{15} \mathrm{O}_{2}\right)$ for blood flow measurements and molecular oxygen $\left({ }^{15} \mathrm{O}_{2}\right)$ for metabolic studies. Regional tissue blood volumes were measured by scanning after circulating red cells had been labelled by inhaling trace amounts of carbon-11 monoxide (11CO). In addition transmission scans using an external source of positron emitting isotope (germanium-68; ${ }^{68} \mathrm{Ge}$ ) were recorded. These were subsequently used for correcting the emission data for tissue attenuation.

The patient was positioned on the bed of the scanner with his legs lying within the scanner's $50 \mathrm{~cm}$ diameter field of view. Accurate positioning was assured by using a narrow laser slit beam which shines from the detector bank on to the patient in the same plane as the detectors. The bed was then adjusted so that the beam fell across the area of ulceration or lipodermatosclerosis on the patient's leg. 
The Hammersmith cyclotron produces the oxygen-15 on site and the gas is continuously piped to the scanner room. The patient continuously inhaled the oxygen through a Ventimask. Ten minutes was allowed to reach a steady state of isotope concentration within the tissues before scanning.

Oxygen-15 is a short lived ( $t \frac{1}{2}=2.1 \mathrm{~min}$ ) positron emitting isotope. When an oxygen-15 nucleus disintegrates a positron is released and captured by a negatively charged electron in the tissues. This results in the annihilation of both particles and the production of a pair of photons which are emitted at 180 degrees to each other. The detection of these simultaneously emerging pairs of photons is called "coincidence detection" and enables their site of origin to be determined. In this way by using the emission computerised axial tomograph the in vivo distribution of the radionuclide was measured. The history and theory of this technique was reviewed by Jones. ${ }^{12}$

The oxygen-15 steady state technique for measuring regional tissue blood flow and oxygen utilisation using positron emission tomography was described in detail by Frackowiak et al, ${ }^{11}$ who developed the method for studying brain tissue. During the continuous inhalation of $\mathrm{C}^{15} \mathrm{O}_{2}$ the label is transferred to pulmonary water and hence there is a constant arterial supply of $\mathrm{H}_{2}{ }^{15} \mathrm{O}$. Because of the short half life of oxygen-15 the resulting steady state tissue concentration of $\mathrm{H}_{2}{ }^{15} \mathrm{O}$ is dependent on blood flow. Jones et al $^{10}$ described this dependence and formulated the relation between flow and the corresponding arterial concentration of $\mathrm{H}_{2}{ }^{15} \mathrm{O}$. When continuously inhaling ${ }^{15} \mathrm{O}_{2}$ the red cells become labelled and hence oxygen-15 is offered to the tissues for respiration in the normal way. Tissue respiration results in the oxygen-15 being transferred to the water of metabolism within the tissues. Again formulas have been described which represent the relation between the tissue's steady state $\mathrm{H}_{2}{ }^{15} \mathrm{O}$ metabolism concentration and the corresponding arterial concentration of ${ }^{15} \mathrm{O}_{2}$.

To solve these equations and interpret the scans it is necessary to measure the arterial concentrations of the isotopes. To achieve arterial sampling a fine cannula was placed in the radial artery under loca anaesthesia before beginning the procedure.

This research project was approved by the research ethical committee of the Royal Postgraduate Medical School and the management team of the North Hammersmith District, and written, informed consent was obtained from all patients.

\section{Results}

The emission scans are processed by an on line computer using the additional measurements made on the arterial blood samples. The calculations are solved pixel by pixel to produce both images on screen and numerical computer printout.

Figure 1 shows the image data for blood flow and fig 2 the image data for oxygen extraction ratio produced by scanning a patient with a lateral ulcer on her left leg. The ulcer bearing area showed a high blood flow and a low oxygen extraction ratio. Figures 3 and 4 show blood flow and oxygen extraction ratio scans in a patient who had never had venous ulceration but who did have calf muscle pump failure and liposclerosis. Similar changes were observed as those seen in the ulcerated leg.

Numerical evaluation of the data was taken from the computer printouts. In legs with ulcers the number of pixels counted was determined by the size of the ulcer in the plane of the scan. A region

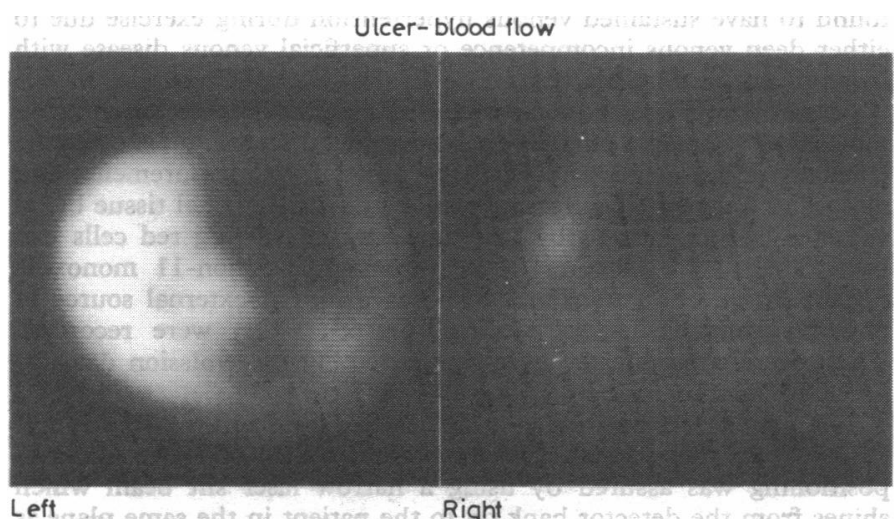

FIG 1-Blood flow images in patient with left lateral ulcer showing high blood flow in ulcer bearing area.

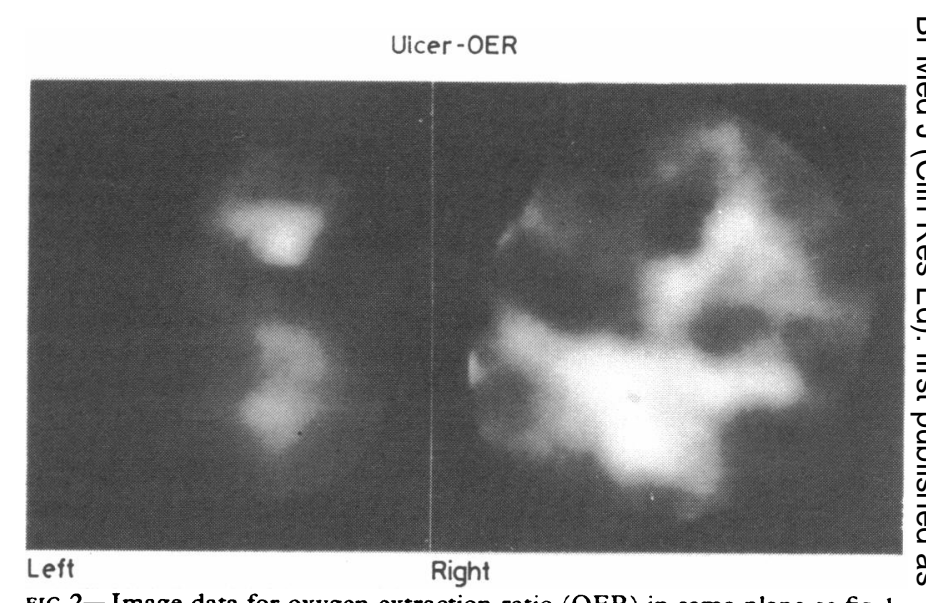

FIG 2-Image data for oxygen extraction ratio (OER) in same plane as fig 1, showing low ratio in ulcer bearing area.

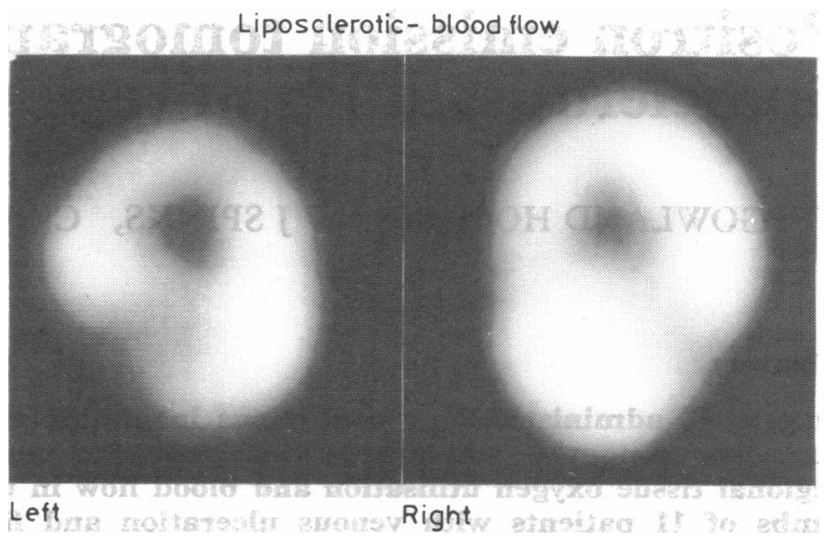

FIG 3-Blood flow images in patient with bilateral liposclerosis but no ulceration. Areas of diseased tissue have high blood flow.

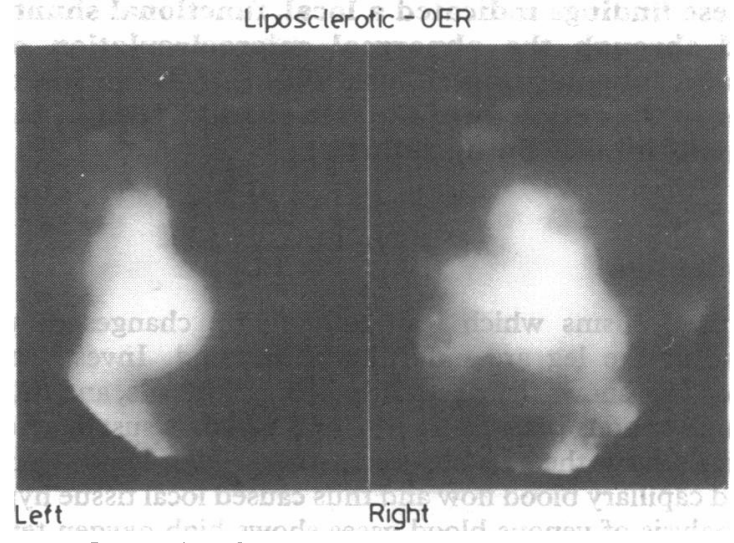

FIG 4-Image data for oxygen extraction ratio (OER) in same plane as fig 3 , showing low ratio in areas of liposclerosis.

of interest four pixels wide was used in all scans to define the area for analysis. A similar method was used for legs with lipodermatosclerosis, although the limits of abnormal tissue were less easily defined.

Figure 5 shows the values of regional blood flow obtained from the ulcer bearing areas of 11 patients with venous ulceration. In patients with unilateral disease this value was compared with the anatomically $\mathbb{\mathbb { D }}$ equivalent area of the normal leg and a $U$ test of significance applied. All differences were highly significant (at $1 \%$ level). Figure 6 shows the oxygen extraction ratios in the 11 patients. Two scans showed unacceptably high ratios (see Discussion).

Figure 7 shows the regional blood flow values in five cases of liposclerosis. All the patients had bilateral disease ; hence for compari- 


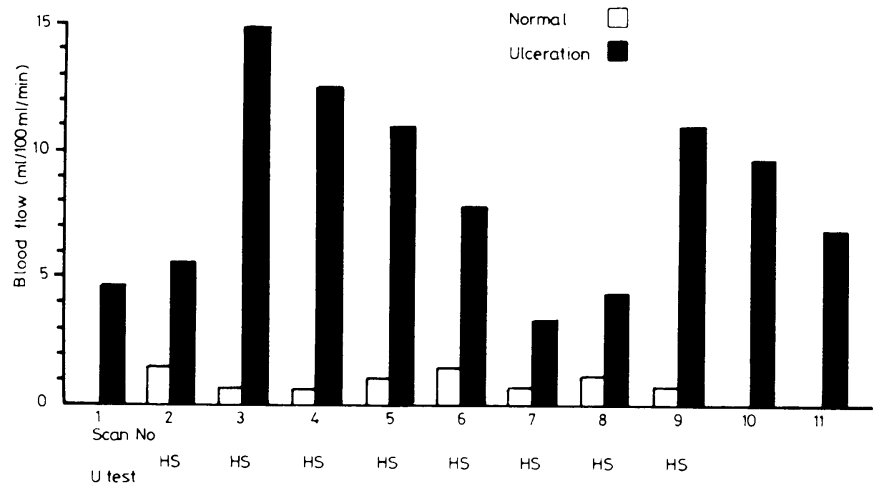

FIG 5-Values of regional blood flow in ulcer bearing area of 11 patients with venous ulceration. Normal values obtained by analysing anatomically equivalent area of normal leg in patients with unilateral disease. Three patients had bilateral disease. ( $\mathrm{HS}=$ Statistically highly significant at $1 \%$ level.)

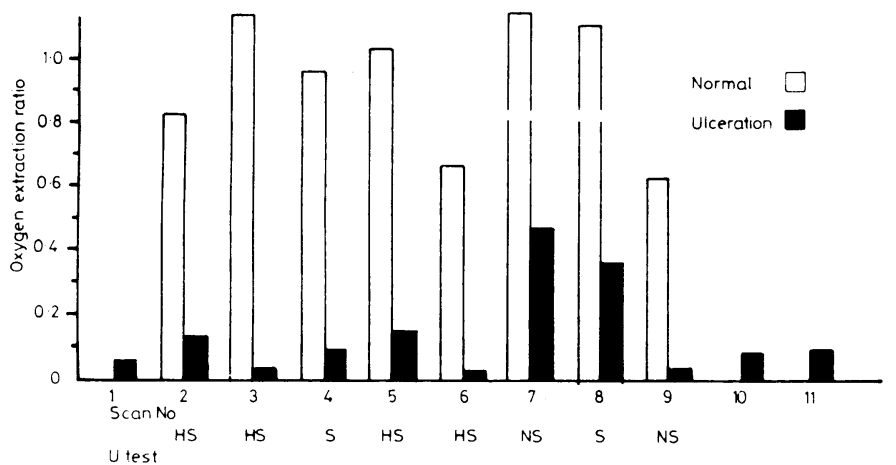

FIG 6-Values of oxygen extraction ratio equivalent to flow values in fig 5 . (NS = Statistically not significant. $\mathrm{S}=$ Significant at $5 \%$ level. $\mathrm{HS}=\mathrm{Highly}$ significant at $1 \%$ level.)

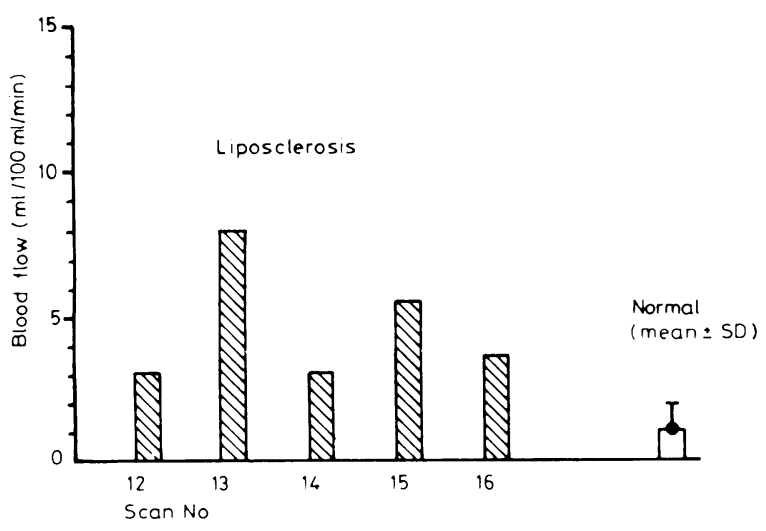

FIG 7-Values of regional blood flow from five cases of liposclerosis. All patients had bilateral disease. Mean $\pm S D$ of all normal studies in series shown for comparison.

son fig 7 also shows the mean value and standard deviation from all the normal studies in the series. These were composed of one study of a normal subject (two legs) and studies of eight normal legs of patients who had unilateral disease. Figure 8 shows the oxygen extraction ratios in the five patients.

The table gives the numerical data in figs $5,6,7$, and 8 . In each scan the blood flow in the diseased tissue was significantly greater than in the normal area. The values obtained for oxygen extraction ratio were lower in the ulcer bearing and lipodermatosclerotic areas than in the normal areas. The differences were statistically significant in all but scans 7 and 9. In these, despite the great difference between normal and abnormal areas, the $U$ test failed to reach significance as a result of a high standard deviation in the values for the normal limb. The reason for the great variation in pixel counts in these two scans was not clear but may have been due to the area of interest containing relatively avascular structures such as tendon at one extreme or groups of blood vessels at the other.

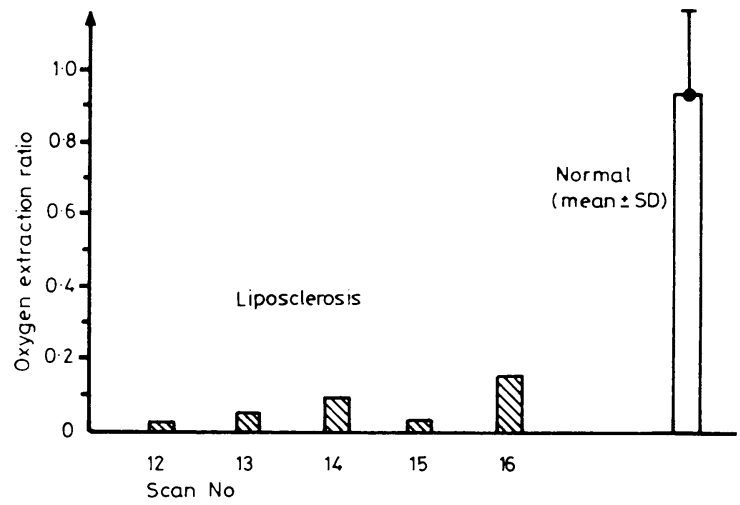

FIG 8-Oxygen extraction ratios equivalent to blood flow values in fig 7 .

\section{Discussion}

Oxygen-15 is an interesting radionuclide for in vivo tracer studies. When used as ${ }^{15} \mathrm{O}_{2}$ it may be introduced into the body by inhalation, and in turn its tissue concentration reflects direct oxygen utilisation. In the form of $\mathrm{C}^{15} \mathrm{O}_{2}$, where its tracer moves to $\mathrm{H}_{2}{ }^{15} \mathrm{O}$, an inert marker of tissue blood flow is provided. Earlier detectors such as scanning probes and gamma cameras provided a two dimensional picture. The development of systems to measure the distribution of isotopes tomographically has enabled regional tissue function to be studied accurately..$^{13-16}$

Previously for quantitative measurements the isotope had to be administered intra-arterially as $\mathrm{H}_{2}{ }^{15} \mathrm{O},{ }^{15} \mathrm{O}$-oxyhaemoglobin, or $\mathrm{C}^{15} \mathrm{O}$-carboxyhaemoglobin, the data being collected-usually with probes over a short period of time-during a single passage of the isotope through the tissue. ${ }^{1718}$ The continuous inhalation model developed by Jones et al in $1976^{12}$ enables studies to be performed with a steady state distribution of radioactivity and makes the method non-invasive and suitable for clinical use. The method has been validated experimentally in animals ${ }^{19}$ and is now being extensively used to study cerebral metabolism ${ }^{11}$ and also tumours and peripheral vascular disease. ${ }^{20} 21$

Venous disease of the leg has never been studied using positron emission tomography, since previous investigations were confined to two dimensional studies. The method appears to be suitable for studying this disease process and the results show consistent abnormalities in the pathological areas.

There are two particular problems which affect the quantitative results obtained. Firstly, full recovery of the tissue concentration of tracer can be achieved only if the dimensions of the regions analysed are greater than twice the full resolution width of the scanner $(2 \times 16 \mathrm{~mm})$. Because venous ulceration is superficial and smaller than $32 \mathrm{~mm}$ quantitative values of flow and oxygen utilisation obtained will be underestimated ("partial volume effect" ${ }^{22}$ ). This inaccuracy, however, will be common to both diseased and normal tissues studied. Secondly, the leg is a vascular structure with a high blood volume. In this study the values obtained for oxygen extraction were subjected to a correction factor based on the values obtained for blood volume in the ${ }^{11} \mathrm{CO}$ scans. This correction factor assumes that all the blood measured is venous. This is clearly an oversimplification. At high oxygen extraction ratios and blood volumes and low values of flow this uncertainty has a more pronounced effect on the calculated oxygen extraction ratios. This may help to explain the unacceptably high oxygen extraction ratios in scans 7 and 8 
Numerical data from all scans in series, and results of $U$ tests for scans of patients with unilateral disease. Values expressed $\pm S D$

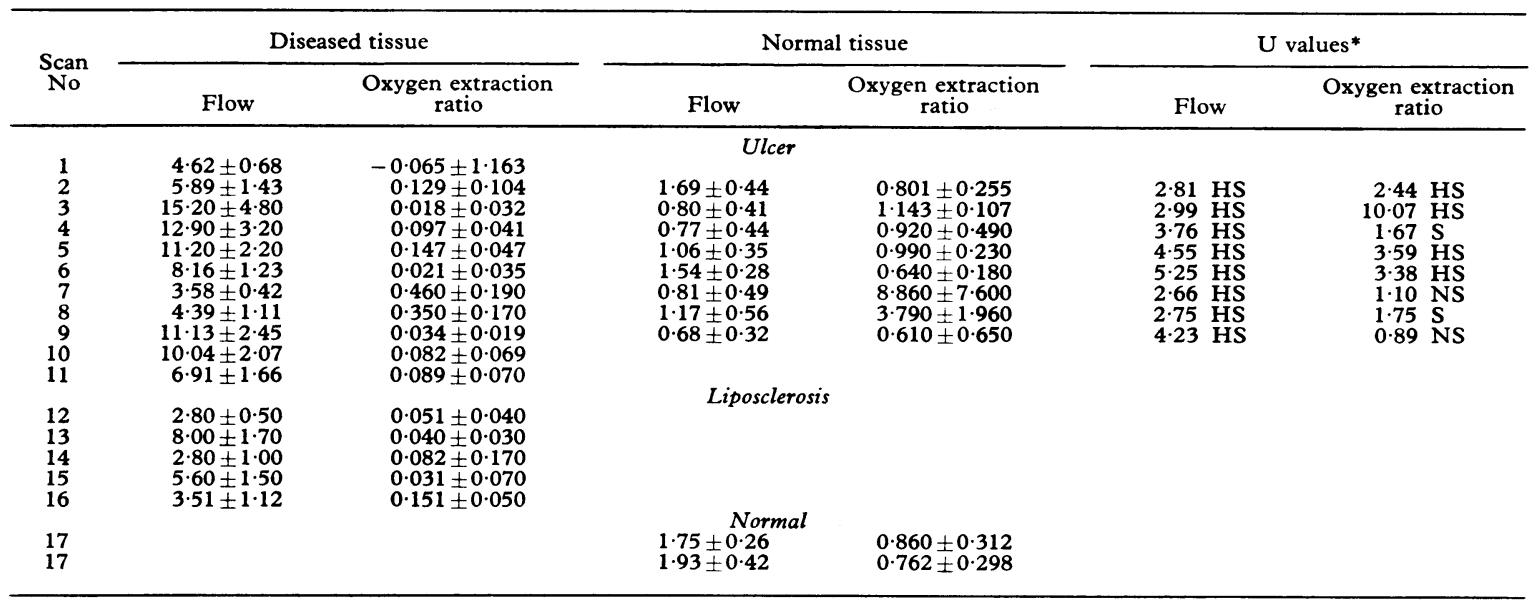

*NS = Not statistically significant. $S=$ Significant at $5 \%$ level. $\mathrm{HS}=$ Highly significant at $1 \%$ level.

in the normal tissue zones. The values obtained in diseased areas will be less affected by this correction because the oxygen extraction ratio is low and flow is high.

These findings provide a map of regional tissue physiology which supports the histopathological changes reported by Burnand et al. ${ }^{7-9}$ They detected a vast proliferation of capillaries in the diseased subcutaneous tissues of patients with venous liposclerosis or ulceration or both. This is supported by our findings of greatly increased blood flow at these sites. They also found that these numerous capillaries had walls surrounded by fibrin cuffs, which they postulated would impair their diffusive capabilities. This hypothesis also receives strong support from our finding of grossly impaired oxygen extraction in these areas.

Interestingly none of our patients' ulcers or liposclerosis could be blamed on varicose veins alone. Each had a gross abnormality of the deep venous system on careful investigation. The role of purely superficial venous incompetence in the pathophysiology of venous skin changes remains unidentified.

We express our gratitude to the engineering department and the department of radiochemistry of the MRC Cyclotron Unit for their role in producing the isotopes used in this study, and to $T$ Jones (head of physics, isotope section) for his help throughout the study and during the preparation of the manuscript.

\section{References}

${ }^{1}$ Homans J. The etiology and treatment of varicose ulcer of the leg. Surg Gynecol Obstet 1917;24:300-15.

2 Holling HE, Beecher HK, Linton RR. Study of the tendency to edema formation associated with incompetence of valves of communicating veins of the leg. Oxygen tension of blood contained in varicose veins. f Clin Invest 1938;17:555-61.

${ }^{3}$ Pialachs P, Vidal-Barraquer F. A pathogenic study of varicose veins. Angiology 1953;4:59-65.

4 Gius JA. Arteriovenous anastomoses and varicose veins. Arch Surg 1960; 81 :299-308.

${ }^{5}$ Ryan TJ, Copeman PWM. Microvascular pattern and skin stasis in skin disease. Br F Dermatol 1969;81:563-70.

${ }^{6}$ Lindemayn W, Loefferer O, Mostbeck A. Arteriovenous shunts in primary varicosis? A critical essay. Vasc Surg 1972;6:9-14.

7 Burnand KG, Whimster I, Clemenson G, Lea Thomas M, Browse NL. The relationship between the number of capillaries in the skin of the venous ulcer-bearing area of the lower leg and the fall in foot vein pressure during exercise. Br F Surg 1981;68:297-300.

${ }^{8}$ Burnand KG, Clemenson G, Whimster I, Gaunt J, Browse NL. The effect of sustained venous hypertension on the skin capillaries of the canine hind limb. Br $\mathcal{F}$ Surg 1982;69:41-4.

${ }^{9}$ Burnand KG, Clemenson G, Whimster I, Browse NL. Extravascular fibrin deposition in response to venous hypertension-the cause of venous ulcers. Br $\mathcal{f}$ Surg 1976;63:660.

${ }^{10}$ Jones T, Chesler DA, Ter-Pogossian MM. The continuous inhalation of ${ }^{15} \mathrm{O}_{2}$ for assessing regional oxygen extraction in the brain of man. $\mathrm{Br} \mathcal{F}$ Radiol 1976;49:339-43.
11 Frackowiak RSJ, Lenzi G-L, Jones T, Heather JD. Quantitative measurement of regional cerebral blood flow and oxygen metabolism in man using ${ }^{15} \mathrm{O}$ and positron emission tomography; theory, procedure and $\mathrm{N}$ normal values. $\mathcal{f}$ Comput Assist Tomogr 1980;4(6):727-36.

12 Jones T. Positron emission tomography and measurements of regional $\omega$ tissue function in man. Br Med Bull 1980;36(3):231-6.

13 Phelps ME, Hoffman EJ, Mullani NA, Ter-Pogossian MM. Application 을 of annihilation coincidence detection to transaxial reconstruction $N$ tomography. F Nucl Med 1975;16:210-24.

14 Ter-Pogossian MM, Phelps ME, Hoffman EJ, Mullani NA. A positron cั emission transaxial tomograph for nuclear imaging (PETT). Radiology $1975 ; 114: 89-98$.

15 Phelps ME, Hoffman EJ, Huang S-C, Kuhl DE. ECAT; a new computerised tomographic imaging system for positron emitting radiopharma- $\vec{\theta}$ ceuticals. F Nucl Med 1978;19:635-7.

16 Williams CW, Crabtree MC, Burgess SG. Design and performance $\omega$ characteristics of a positron emission computed axial tomograph. ECAT 11. IEEE Transactions on Nuclear Sciences (NS) 1979;26:619-27.

17 Ter-Pogossian MM, Eichling JO, Davis DO, Welch MJ, Metzgar JM. The determination of regional cerebral blood flow by means of water $\overline{0}$ labelled with radioactive oxygen-15. Radiology 1969;93:31-40.

18 Ter-Pogossian MM, Eichling JO, Davis DO, Welch MJ. The measure- 음 ment in vivo of regional cerebral oxygen utilisation by means of oxyhemoglobin labelled with radioactive oxygen-15. F Clin Invest 1970;49:381-91. $\overrightarrow{\vec{\sigma}}$

19 Rhodes CG, Lenzi GL, Frackowiak RS J, Jones T, Pozzilli C. Measurement of $\mathrm{CBF}$ and $\mathrm{CMRO}_{2}$ using the continuous inhalation of $\mathrm{C}^{15} \mathrm{O}_{2}$ and ${ }^{15} \mathrm{O}_{2}$. Experimental validation using $\mathrm{CO}_{2}$ reactivity in the anaesthetised dog. f Neurol Sci $1981 ; 50: 381-9$.

${ }^{20}$ Gronemeyer SA, Brownell GL, Elmaleh DR, Athanasoulis CA. Transverse section imaging of soft tissue tumours and peripheral vascular disease. Semin Nucl Med 1980;10(4):392-9.

${ }^{21}$ Clyne CAC, Jones T, Moss S, Ensell J. The use of radioactive oxygen to study muscle function in peripheral vascular disease. Surgery 1979; 149:225-8.

${ }^{22}$ Hoffman EJ, Huang S-C, Phelps ME. Quantitation in positron emission computed tomography; 1. Effect of object size. $\mathcal{F}$ Comput Assist Tomogr $1979 ; 3: 299-308$.

(Accepted 8 December 1982)

ONE HUNDRED YEARS AGO A good deal has been written from time to time as to the dangerous influence of strong tea on the nerves. Apparently, the Devonport Board of Commissioners are $\stackrel{\mathbb{S}}{\rightarrow}$ determined to spare the nerves of the patients under their charge from the slightest risk of deterioration from this cause. The Lunacy Commissioner inspecting the wards found that, in the fluid distributed $\stackrel{\mathbb{D}}{\mathrm{D}}$ as tea in that workhouse, one ounce of tea is allowed for fourteen

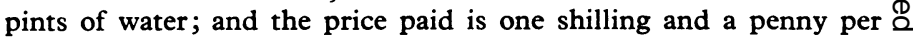
pound. The correctness of the statement was questioned by one of $\bar{\sigma}$ the members, but the chairman indicated that it was correct. At any rate, the inmates are not likely to be kept awake by the undue strength 응 of the beverage which is served out to them. Is not this carrying economy and consideration much too far? (British Medical fournal, $\frac{\overline{0}}{7}$ 1883 ;ii :78.) 